\title{
Anti-hypoxia Activity of the Novel NO Donor Acetyl Ferulic Isosorbide Mononitrate in Acute High-Altitude Hypoxia Mice
}

\author{
Peng-Cheng Fan, ${ }^{a}$ Hui-Ping Ma, ${ }^{a}$ Wei Jiang, ${ }^{b}$ Lin Li,${ }^{b}$ Jun Ren,,${ }^{a}$ Lin-lin Jing, ${ }^{*, a}$ and \\ Zheng-Ping Jia ${ }^{*}, a$ \\ ${ }^{a}$ Department of Pharmacy, General Hospital of Lanzhou Command of PLA; Lanzhou 730050, China: and \\ ${ }^{b}$ Department of Pharmaceutics, School of Pharmacy, Lanzhou University; Lanzhou 730000, China. \\ Received February 11, 2015; accepted June 4, 2015
}

\begin{abstract}
Nitric oxide (NO) may act as either a pro-oxidant or an antioxidant in biological systems. Previous work has found inhalation of NO improved survival in a high altitude rat model. NO donor isosorbide mononitrate derivants might have a protective effect against hypoxia. We synthesized a series of isosorbide mononitrate derivant compounds to test their anti-hypoxia activities. Normobaric hypoxia and hypobaric hypoxia models were used to study the protective role of NO donor in mice. The results showed isosorbide mononitrate derivants had protective effects in hypoxia mice. Among those compounds, acetyl ferulic isosorbide mononitrate (AFIM) was the most effective. It prolonged the survival time during the normobaric hypoxia test. It decreased malondialdehyde (MDA) and $\mathrm{H}_{2} \mathrm{O}_{2}$ in hypobaric hypoxia mice. The antioxidase activities of superoxide dismutase (SOD), glutathione peroxidase (GSH-Px) and catalase (CAT) remained in normal ranges in the AFIM group. As a sign of mitochondrial dysfunction, the activities of ATPase were down regulated in mice under hypobaric hypoxia conditions. AFIM also protected ATPase activities. The protective effects of AFIM might come from a sustained NO supply and the release of acetyl ferulic acid with anti-oxidant activity.
\end{abstract}

Key words altitude; hypoxia; nitric oxide; acetyl ferulic isosorbide mononitrate

More than $140 \mathrm{M}$ persons lives at above $2500 \mathrm{~m}$ (the conventional definition of high altitude as that where arterial $\mathrm{O}_{2}$ saturation $\left(\mathrm{SaO}_{2}\right)$ measurably begins to fall). ${ }^{1}$ Barometric pressure falls with increasing altitude and consequently there is a reduction in the partial pressure of oxygen resulting in a hypoxic challenge to any individual ascending to altitude. With the ever increasing number of people ascending to high altitudes, medicines to deal with potential problems are becoming increasingly relevant to non-specialists, including general practitioners.

A spectrum of high altitude illnesses can occur when the hypoxic stress outstrips the subject's ability to acclimatize. Acute mountain sickness (AMS) and high-altitude cerebral edema (HACE) strike people who travel too fast to high altitudes that lie beyond their current level of acclimatization. ${ }^{2)}$ AMS is a condition affecting otherwise healthy individuals on going rapidly to altitude. A spectrum of symptoms related to acute mountain sickness may develop at altitudes below $3000 \mathrm{~m}$ : commonly reported symptoms are nausea, vomiting, headache, dizziness, fatigue, and sleep disturbance. ${ }^{3)}$ Acute hypoxia induces pulmonary vascular permeability and contributes to forms of noncardiogenic pulmonary edema such as high altitude pulmonary edema and acute respiratory distress syndrome. ${ }^{4,5)}$ AMS can sharply limit recreation and work at high altitude, especially in the first few days following arrival at a new, higher altitude, and if AMS worsens and HACE develops, the risk of fatality is significant. $\left.{ }^{6}\right)$ Although slow ascent to altitude remained the most important measure to prevent acute mountain sickness, evidence from the literature on high altitude suggested that drugs could complement gradual ascent in preventing acute mountain sickness. ${ }^{7)}$ Treatment typically occurred on the mountainside, but seeking to prevent acute mountain sickness begins before the ascent to high altitude (generally $>3000 \mathrm{~m}$ ). More and more studies were concerned on the prophylaxis and therapy of AMS. ${ }^{8-11)}$

Nitric oxide (NO) is a gaseous signaling molecule that participates in a large variety of physiological functions and may have a role in the pathology of altitude illnesses, such as acute mountain sickness (AMS). ${ }^{12)}$ It plays an important role in people's adaptation to high altitude hypoxia. Erzurum et al. found Tibetans had $>10$-fold-higher circulating concentrations of bioactive nitric oxide products in comparison to sea level controls, which suggested that NO production was increased and that metabolic pathways controlling formation of NO products were regulated differently among Tibetans. Those findings shifted attention from the traditional focus on pulmonary and hematological systems to vascular factors contributing to adaptation to high-altitude hypoxia. ${ }^{13)}$ Hoit $e t$ $a l$. found that $\mathrm{NO}$ in the lung might play a key beneficial role in allowing Tibetans at $4200 \mathrm{~m}$ to compensate for ambient hypoxia with higher pulmonary blood flow and $\mathrm{O}_{2}$ delivery without the consequences of higher pulmonary arterial pressure. ${ }^{14)}$ Macinnis et al. found that subjects who developed AMS had a significantly lower mean exhaled NO at baseline compared to resistant subjects. ${ }^{12)}$ Respiratory NO synthesis was suggested to represent a protective mechanism against hypoxic pulmonary hypertension. ${ }^{13-15)}$

Whether supplement of exogenous NO was beneficial or futile remained uncertain. ${ }^{16)}$ Scherrer et al. found that the inhalation of NO improved arterial oxygenation in high-altitude pulmonary edema, and the beneficial effect might be related to its favorable action on the distribution of blood flow in the lungs. ${ }^{17)}$ Inhaled NO improved survival in high altitude pulmonary edema (HAPE) rat model and might have a therapeutic role in the management of HAPE. The combined using of inhaled NO and oxygen had additive effects on pulmonary hemodynamic and even greater effects on gas exchange. ${ }^{18,19)}$ Whether intravenous administration NO donor compounds 
had the same beneficial effects as inhaled NO for circulatory system and nervous system remained unclear. For answer this question we synthesized $6 \mathrm{NO}$ donor compounds as source of exogenous NO and screened their anti-hypoxia activities by the survival time of the mice under normobaric hypoxia. Among those compounds, acetyl ferulic isosorbide mononitrate (AFIM) was the most effective one. The aim of current work was to study the effect of NO donor to AMS in acute high-altitude hypoxia mice model in vivo. Acetazolamide (ACZ) was one of the unequivocally effective drugs. ${ }^{11,20-22)}$ But it had some side effects such as memory impairment ${ }^{23)}$ and decreased exercise capacity. ${ }^{24)}$ We chose ACZ as positive control to compare the effects of AFIM and ACZ. In the first step of the present study, the NO donor compounds were prepared using the literature reported procedures. ${ }^{25)}$

\section{MATERIALS AND METHODS}

Drugs and Chemicals The formulae of NO donor compounds and their general synthesis processes were listed in Fig. 1. Briefly, acetyl acid (compounds 1-6, $10 \mathrm{mmol}$ ), isosorbide mononitrate $(1.91 \mathrm{~g}, 10 \mathrm{mmol}$, CAS No. 16051-77-7, $[\alpha]_{\mathrm{D}}=168^{\circ}(c=1.0$, ethanol $\left.(\mathrm{EtOH}))\right)$ and dimethylallylpyrophosphate (DMAP) $(0.24 \mathrm{~g}, 1 \mathrm{mmol})$ were dissolved in $100 \mathrm{~mL}$ dry tetrahydrofuran (THF), then dicyclohexylcarbodiimide (DCC) $(4.12 \mathrm{~g}, 10 \mathrm{mmol})$ was added to the solution at $0^{\circ} \mathrm{C}$. The mixture was stirred at room temperature for $5 \mathrm{~h}$. The resulting mixture was filtered and concentrated in vacuo. The crude product was purified by column chromatography over silica gel using ethyl acetate- $n$-hexane $(7: 3)$ as eluent. The compounds A-F ( $83-88 \%$ yield) was obtained as white powder. The structures of NO donor compounds were determined by IR, MS, and NMR. Column chromatography was carried out with silica gel 60 Merck for purification, and the purity of NO donor compounds was $99 \%$. Stock solution of NO donor compounds $(25 \mathrm{~mm})$ was prepared with dimethyl sulfoxide (DMSO) and stored at $-20^{\circ} \mathrm{C}$ for in vitro test. The stock solution was further diluted with the appropriate assay medium immediately before use. While in vivo test AFIM was prepared with physiological saline before use. ACZ included as a positive control was purchased from Sigma-Aldrich (St. Louis, MO, U.S.A.). The measurement kits for lactate dehydrogenase (LDH), Lactic acid (LAC), bicinchoninic acid (BCA) protein assay, superoxide dismutase (SOD), glutathione peroxidase (GSH-Px), catalase (CAT) and ATPase activities assay kits were obtained from Nanjing Jiancheng Bioengineering Institute (Nanjing, China).

Animals All BALB/c mice $(22 \pm 2 \mathrm{~g})$ used in this experiment were SPF animals and obtained from the Center for Experimental Animals, Lanzhou Institute of Biological Products (Lanzhou, China). The mice were housed in the Laboratory Animal Care Center of Lanzhou Command General Hospital (elevation $1520 \mathrm{~m}$ ). Animals were allowed access to food and water ad libitum. The animals were kept on a 12-h day-night cycle. All experimental protocols were reviewed and approved by the Institutional Animal Care and Use Committee at the Lanzhou Command General Hospital. The mice were divided into nine groups with ten animals in each group, (1) Normal control, (2) model, (3) ACZ $200 \mathrm{mg} / \mathrm{kg}$, (4)-(9) compounds A-F $100 \mathrm{mg} / \mathrm{kg}$.

Effect of NO Donors on Survival Time of Mice under Normobaric Hypoxia Airtight anoxia experiment was used to measure the anti-hypoxia effect of NO donors for normobaric hypoxia. ${ }^{21,26)}$ In the normobaric hypoxia test, groups of overnight fasted mice were treated by vena caudalis administration with five NO donors $(100 \mathrm{mg} / \mathrm{kg})$, AFIM (50, 75, $100 \mathrm{mg} / \mathrm{kg})$, vehicle $(10 \mathrm{~mL} / \mathrm{kg}$ physiological saline) or $\mathrm{ACZ}$ $(200 \mathrm{mg} / \mathrm{kg})$. Twenty minutes after administration, each mouse was put into a $250 \mathrm{~mL}$ airtight container with $5 \mathrm{~g}$ medical soda lime inside. The bottle neck was treated with petroleum jelly for a hermetic condition. Bottle cap was sealed after mouse was put into the bottle. Time from bottle cap sealed to mouse stopped breathing was recorded as survival time. The survival time of oxygen deprivation and prolongation rate (prolongation rate $=($ survival time of treatment group - survival time of model group)/survival time of model group) were used

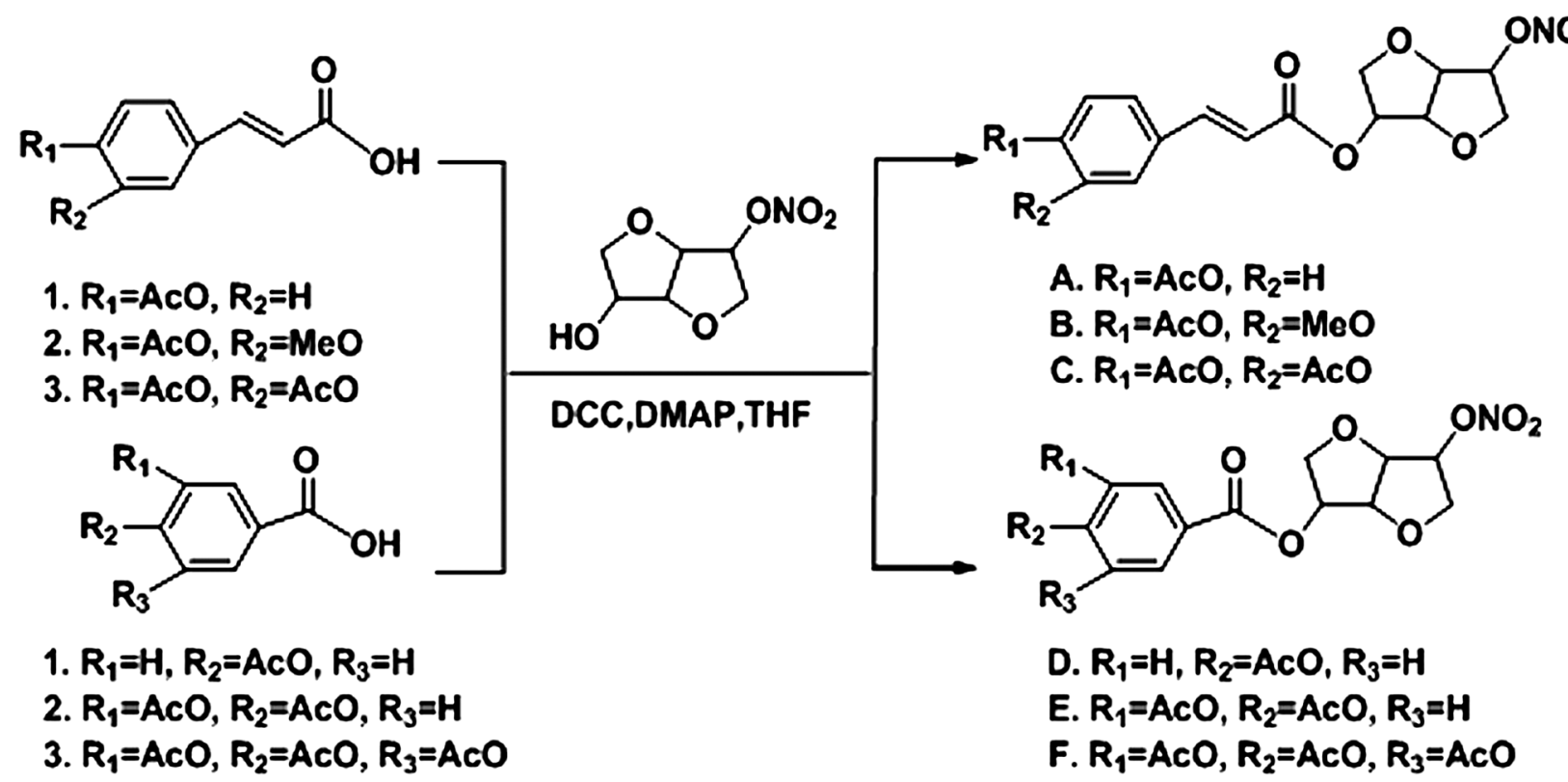

Fig. 1. Chemical Structure and General Synthesis Processes of NO Donor Compounds 
to compare the anti-hypoxic activity. As soon as the mouse stopped breathing, the thorax was opened, about $0.5 \mathrm{~mL}$ blood sample was withdrawn from heart and $0.4 \mathrm{~mL}$ was added to the centrifuge tube citrate-stabilized with $3 \%$ natrium citricum. The mixture was centrifuged at $2500 \boldsymbol{g}$ for $5 \mathrm{~min}$. The plasma was collected and used to determine the concentration of lactic acid and lactate dehydrogenase.

Lactic Acid (LD), LD Accumulation Rate and LDH Assessment To assess the $\mathrm{LD}, \mathrm{LD}$ accumulation rate and $\mathrm{LDH}$, blood samples were collected, centrifuged and kept at $-20^{\circ} \mathrm{C}$ until analyses. ${ }^{27)}$ Standard techniques using commercialized assay kits according to the manufacturer's instructions (Nanjing Jiancheng Bioengineering Institute, China) were performed for analysis. LD accumulation rate were calculated as $\mathrm{LD} /$ survival time. $\mathrm{LD}$ values were expressed as mmol/L. $\mathrm{LD}$ accumulation rates were expressed as $\mu \mathrm{mol} / \mathrm{L} \cdot \mathrm{min} . \mathrm{LDH}$ values were expressed as $\mathrm{U} / \mathrm{L}$.

Effect of NO Donors on Heart Rate and Blood Pressure of Rats under Hypobaric Hypoxia Test We used large low pressure oxygen compartment (Guizhou Fenglei, China) to stimulate high-altitude condition. NO donors and ACZ were administrated as mentioned above. Twenty minutes after being administrated with NO donors or vehicle by vein, rats except normal control group were put into the hypobaric hypoxia compartment and decompressed at a speed of $100 \mathrm{~m} / \mathrm{min}$. At last the simulated altitude of $8000 \mathrm{~m}$ was obtained. Rats were adapted to this hypobaric hypoxia environment ( $8 \%$ oxygen and $92 \%$ nitrogen, $0.035 \mathrm{MPa})$ for $12 \mathrm{~h}$ and then recovered to altitude of $4500 \mathrm{~m}(100 \mathrm{~m} / \mathrm{min}, 0.06 \mathrm{MPa})$. Meanwhile the experimenters entered the large low pressure oxygen compartment through a transfer chamber $(4500 \mathrm{~m})$ and test the blood pressure and heart rate (HR) of rats by BP-2010A Series Blood Pressure Meter (Softron, Japan).

Hypobaric Hypoxia Test We chose the most effective NO donor in normobaric hypoxia test AFIM as the test compound in hypobaric hypoxia test. The method reported by Ma et al. was adjusted and used in this test. ${ }^{21,26)}$ Low Pressure Oxygen compartment (Guizhou Fenglei, China) was used to stimulate high-altitude condition. Sixty BALB/c mice were randomly divided into 6 groups: normal control group, decompression hypoxia model group, ACZ group $(200 \mathrm{mg} / \mathrm{kg})$ and AFIM group $(50,75,100 \mathrm{mg} / \mathrm{kg})$. AFIM and ACZ were administrated as mentioned above. Mice except normal control group were put into a hypobaric hypoxia chamber and decompressed at a speed of $100 \mathrm{~m} / \mathrm{min}, 20 \mathrm{~min}$ after being veinly administrated with AFIM or vehicle. When the simulated altitude of $8000 \mathrm{~m}$ was obtained, mice were adapted to this hypobaric hypoxia environment ( $8 \%$ oxygen and $92 \%$ nitrogen, $0.4 \mathrm{MPa}$ ) for $12 \mathrm{~h}$, and then slowly recovered to normal altitude in half an hour. Opened the chamber door, sacrificed the animals by cervical dislocation. Mice hearts and brains were collected and stored at $-80^{\circ} \mathrm{C}$ which were used for morphological analysis, hydrogen peroxide, malonaldehyde and enzymatic activity assays.

Malondialdehyde (MDA) Assessment The extent of lipid peroxidation in the mouse blood was estimated by MDA level, which was measured by using the spectrophotometric diagnostic kits (Nanjing Jiancheng Biotechnology Institute, China) as described by Uchiyama and Mihara. ${ }^{28,29)}$

$\mathrm{H}_{2} \mathrm{O}_{2}$ Measurement Assay $\mathrm{H}_{2} \mathrm{O}_{2}$ production in tissue homogenate was measured as quantitative index of reactive oxygen species (ROS) generation (indirect indicator of the free radical $\mathrm{O}_{2}^{--}$) by an $\mathrm{H}_{2} \mathrm{O}_{2}$ assay kit (Nanjing Jiancheng Institute, China). $\mathrm{H}_{2} \mathrm{O}_{2}$ in mice cerebrum and myocardium was performed on monitoring at the absorbance at $405 \mathrm{~nm}$ of the molybdenic acid-peroxide complex. The absorbance values were calibrated to a standard graph generated with known content of $\mathrm{H}_{2} \mathrm{O}_{2}$, the unit was defined as $1 \mathrm{mmol}$ of $\mathrm{H}_{2} \mathrm{O}_{2}$ per gram fresh protein. Vehicle and AFIM administration mice were treated under hypobaric hypoxia for $12 \mathrm{~h}$. After $12 \mathrm{~h}$ of exposure, the brains and hearts were grasped and washed with cold physiological saline once then homogenated and centrifuged in refrigerated centrifuge. The supernatant $(100 \mu \mathrm{L})$ was added with $\mathrm{H}_{2} \mathrm{O}_{2}$ assay solution $(100 \mu \mathrm{L})$.

Antioxidant Enzyme Activities To prepare homogenates, the mice cerebral cortex, heart and liver were homogenized with a homogenizer $(400 \mathrm{~g}, 60 \mathrm{~s})$ at $4^{\circ} \mathrm{C}$ in cold buffer $(1 / 9$, tissue/ buffer, w/v) containing $0.01 \mathrm{~mol} / \mathrm{L}$ Tris $-\mathrm{HCl}, 0.1 \mathrm{mmol} / \mathrm{L}$ ethylenediaminetetraacetic acid (EDTA), $0.01 \mathrm{~mol} / \mathrm{L}$ saccharose, $0.8 \%$ saline. ${ }^{30)}$ The tubes with homogenate were kept in ice water for $30 \mathrm{~min}$ and centrifuged at $4^{\circ} \mathrm{C}(2500 \mathrm{~g}, 10 \mathrm{~min})$, as recommended in the assay kits. The supernatant was separated, and then stored at $-80^{\circ} \mathrm{C}$. Supernatant was used for assay of various enzymatic activities. Measurement of protein concentration was estimated using commercial BCA assay kits (Nanjing Jiancheng Institute, China). The activities of SOD, GSH-Px, CAT and ATPase were measured using commercial assay kits (Nanjing Jiancheng Institute, China) according to the manufacturer instructions. Briefly, SOD activities were measured following the reduction of nitrite by a xanthinexanthine oxidase system which was a superoxide anion generator. The activities were expressed as U/mg protein. GSH-Px activities were assayed by the decrease of the GSH, which can be reflected by the alteration of the absorbance at $412 \mathrm{~nm}$. CAT activities were determined by decrease of $\mathrm{H}_{2} \mathrm{O}_{2}$ absorption at $405 \mathrm{~nm}$. The activities of SOD, GSH-Px, CAT and ATPase were expressed as $\mathrm{U} / \mathrm{mg}$ protein, $\mathrm{U} / \mathrm{g}$ protein, $\mathrm{U} / \mathrm{mg}$ protein and $\mu \mathrm{mol} \mathrm{Pi} / \mathrm{mgprot} / \mathrm{h}$, respectively.

Statistical Analysis All data were expressed as the mean \pm standard deviation (S.D.) Data was subjected to ANOVA followed by Student-Newman-Keuls tests. $p \leq 0.05$ was considered significant.

\section{RESULTS}

To determine the protective capability of NO donor against hypoxia, we administrated mice with three concentrations of AFIM and subjected them to oxidative challenge via normobaric hypoxia and hypobaric hypoxia. Our initial aim was to prove whether NO donor compounds could protect mice against oxidative stress caused by high altitude hypoxia. Our study was to estimate the protective effect of the AFIM in vivo compared to a commonly used anti-hypoxia drug, ACZ, and also to identify an appropriate dose that offers beneficial effects with no toxicity. To test whether AFIM could protect mice through the hypobaric hypoxia progress, we carried out both pathology and biochemistry assay to determine the morphology and physiology change during the test.

Synthesis of NO Donors The compound was synthesized according to above method.

Compound A: $(1 S, 4 S, 5 S, 8 R)-8$-Nitrooxy-2,6-dioxabicyclo[3.3.0]octan-4-yl-3-(4-acetoxyphenyl)acrylate

Yield: $83 \%$; mp: $78-79{ }^{\circ} \mathrm{C}$; ${ }^{1} \mathrm{H}-\mathrm{NMR}$ : 7.69 (d, $1 \mathrm{H}, J=15.6 \mathrm{~Hz}$, 
$\mathrm{H}-\mathrm{C}=\mathrm{C}), 7.54(\mathrm{~d}, 2 \mathrm{H}, J=7.8 \mathrm{~Hz}, \mathrm{Ar}-\mathrm{H}), 7.13(\mathrm{~d}, 2 \mathrm{H}, J=7.8 \mathrm{~Hz}$, Ar-H), $6.36(\mathrm{~d}, 1 \mathrm{H}, J=16.2 \mathrm{~Hz}, \mathrm{C}=\mathrm{C}-\mathrm{H}), 5.37$ (s, 2H, Cy-H), 5.04 (s, 1H, Cy-H), 4.57 (s, 1H, Cy-H), 4.11-4.12 (m, 1H, Cy-H), 4.06-4.07 (m, 2H, Cy-H), 3.94 (m, 1H, Cy-H), 2.33 (s, $\left.3 \mathrm{H}, \mathrm{CH}_{3}\right)$; IR $\left(\mathrm{cm}^{-1}\right): 2935,1768,1712,1631,1508,1276,1251$, 1166, 1098, 1098, 911, 851, 750; electrospray ionization (ESI)MS $[\mathrm{M}+\mathrm{H}]^{+}:$380.1; Anal. Calcd for $\mathrm{C}_{17} \mathrm{H}_{17} \mathrm{NO}_{9}: \mathrm{C}, 53.83 ; \mathrm{H}$, 4.52; N, 3.69. Found: C, 53.89; H, 4.43; N, 3.58\%.

Compound B: $(1 S, 4 S, 5 S, 8 R)-8$-Nitrooxy-2,6-dioxabicyclo[3.3.0]octan-4-yl-3-(3-methoxyl-4-acetoxyphenyl)acrylate

Yield: $85 \%$; mp: $162-163^{\circ} \mathrm{C}$; ${ }^{1} \mathrm{H}-\mathrm{NMR}: 7.66$ (d, $1 \mathrm{H}$, $J=16.2 \mathrm{~Hz}, \mathrm{H}-\mathrm{C}=\mathrm{C}), 7.05-7.13(\mathrm{~m}, 3 \mathrm{H}, \mathrm{Ar}-\mathrm{H}), 6.37(\mathrm{~d}, 1 \mathrm{H}$, $J=16.2 \mathrm{~Hz}, \mathrm{C}=\mathrm{C}-\mathrm{H}), 5.38(\mathrm{~s}, 2 \mathrm{H}, \mathrm{Cy}-\mathrm{H}), 5.04(\mathrm{~s}, 1 \mathrm{H}, \mathrm{Cy}-\mathrm{H})$, 4.57 (m, 1H, Cy-H), 4.11-4.13 (m, 1H, Cy-H), 4.05-4.07 (m, 2H, Cy-H), 3.94-3.95 (m, 1H, Cy-H), 3.85 (s, 3H, OCH $), 2.17$ (s. $\left.3 \mathrm{H}, \mathrm{CH}_{3}\right)$; IR $\left(\mathrm{cm}^{-1}\right)$ : 2930, 1760, 1710, 1635, 1625, 1503, 1424, 1270, 1250, 1070, 1040, 915, 855, 750; ESI-MS [M+H] ${ }^{+}$: 410.1; Anal. Calcd for $\mathrm{C}_{18} \mathrm{H}_{19} \mathrm{NO}_{10}$ : C, 52.81; H, 4.68; N, 3.42 . Found: C, 52.91; H, 4.65; N, 3.35\%.

Compound C: $\quad(1 S, 4 S, 5 S, 8 R)-8$-Nitrooxy-2,6-dioxabicyclo[3.3.0]octan-4-yl-3-(3,4-diacetoxyphenyl)acrylate

Yield: $86 \%$; mp: $130-131^{\circ} \mathrm{C}$; ${ }^{1} \mathrm{H}-\mathrm{NMR}: 7.64$ (d, $1 \mathrm{H}$, $J=16.2 \mathrm{~Hz}, \mathrm{H}-\mathrm{C}=\mathrm{C}), 7.40$ (d, 1H, J=8.4 Hz, Ar-H), 7.36 (s, 1H, Ar-H), 7.23 (d, $1 \mathrm{H}, J=8.4 \mathrm{~Hz}, \operatorname{Ar}-\mathrm{H}), 6.37$ (d, $1 \mathrm{H}, J=16.2 \mathrm{~Hz}$, $\mathrm{C}=\mathrm{C}-\mathrm{H}), 5.37$ (s, 2H, Cy-H), $5.03(\mathrm{~s}, 1 \mathrm{H}, \mathrm{Cy}-\mathrm{H}), 4.56(\mathrm{~s}, 1 \mathrm{H}$, Су-H), 4.10-4.12 (m, 1H, Су-H), 4.04-4.07 (m, 2H, Су-H), 3.92-3.94 (m, 1H, Cy-H), $2.31\left(\mathrm{~s}, 6 \mathrm{H}, \mathrm{CH}_{3}\right)$; IR $\left(\mathrm{cm}^{-1}\right)$ : 2917, 1770, 1718, 1636, 1507, 1424, 1285, 1258, 1170, 1095, 1060, 916, 854, 766; ESI-MS $[\mathrm{M}+\mathrm{H}]^{+}:$438.3; Anal. Calcd for $\mathrm{C}_{19} \mathrm{H}_{19} \mathrm{NO}_{11}$ : C, 52.18; H, 4.38; N, 3.20. Found: C, 52.26; H, 4.33; N, 3.06\%.

Compound D: $(1 S, 4 S, 5 S, 8 R)-8-N i t r o o x y-2,6$-dioxabicyclo[3.3.0]octan-4-yl-4-acetoxybenzoate

Yield: $87 \%$; mp: $104-105^{\circ} \mathrm{C}$; ${ }^{1} \mathrm{H}-\mathrm{NMR}: 8.05$ (d, $2 \mathrm{H}$, $J=7.8 \mathrm{~Hz}, \operatorname{Ar}-\mathrm{H}), 7.18$ (d, 2H, J=8.4 Hz, Ar-H), 5.47 (s, H, Cy-H), 5.38 (s, H, Cy-H), 5.06 (s, 1H, Cy-H), 4.62 (s, 1H, Су-H), 4.12-4.16 (m, 1H, Сy-H), 4.06-4.10 (m, 2H, Су-H), $3.94(\mathrm{~m}, 1 \mathrm{H}, \mathrm{Cy}-\mathrm{H}), 2.33\left(\mathrm{~s}, 3 \mathrm{H}, \mathrm{CH}_{3}\right)$; IR $\left(\mathrm{cm}^{-1}\right)$ : 2952, 1756, 1714, 1639, 1601, 1504, 1415, 1280, 1220, 1198, 1115, 1015, 920, 864, 766; ESI-MS [M+H] ${ }^{+}:$354.0; Anal. Calcd for $\mathrm{C}_{15} \mathrm{H}_{15} \mathrm{NO}_{9}$ : C, 51.00; H, 4.28; N, 3.96. Found: C, 51.08; H, 4.33; N, 3.92\%.
Compound E: $(1 S, 4 S, 5 S, 8 R)-8$-Nitrooxy-2,6-dioxabicyclo[3.3.0]octan-4-yl-3,4-diacetoxybenzoate

Yield: $88 \%$; mp: $106-107^{\circ} \mathrm{C}$; ${ }^{1} \mathrm{H}-\mathrm{NMR}: 7.93$ (d, $1 \mathrm{H}$, $J=7.8 \mathrm{~Hz}$, Ar-H), 7.84 (s, 1H, Ar-H), 7.29 (d, $1 \mathrm{H}, J=7.8 \mathrm{~Hz}$, Ar-H), 5.47 (s, H, Cy-H), 5.38 (s, H, Cy-H), 5.05 (s, 1H, Cy-H), 4.48 (s, 1H, Cy-H), 4.17-4.17 (m, 1H, Cy-H), 4.09-4.19 (m, 2H, Cy-H), 3.93 (m, 1H, Cy-H), 2.32 (s, 6H, $\left.\mathrm{CH}_{3}\right)$; IR $\left(\mathrm{cm}^{-1}\right)$ : 2941, 1769, 1722, 1646, 1628, 1499, 1425, 1275, 1207, 1163, 1095, 1054, 909, 847, 764; ESI-MS [M+H] ${ }^{+}$: 412.1; Anal. Calcd for $\mathrm{C}_{17} \mathrm{H}_{17} \mathrm{NO}_{11}$ : C, 49.64; H, 4.17; N, 3.41. Found: C, 49.74; H, 4.23; N, 3.33\%.

Compound F: $(1 S, 4 S, 5 S, 8 R)-8$-Nitrooxy-2,6-dioxabicyclo[3.3.0] octan-4-yl-3,4,5-triacetoxybenzoate

Yield: $86 \%$; mp: $152-153^{\circ} \mathrm{C}$; ${ }^{1} \mathrm{H}-\mathrm{NMR}$ : 7.77 (s, 2H, Ar-H), 5.47 (s, H, Cy-H), 5.38 (s, H, Cy-H), 5.04 (s, 1H, Cy-H), 4.58 (s, 1H, Cy-H), 4.14-4.16 (m, 1H, Су-H), 4.08-4.10 (m, 2H, Cy-H), 3.94 (m, 1H, Cy-H), 2.38 (s, 9H, $\left.\mathrm{CH}_{3}\right)$; IR $\left(\mathrm{cm}^{-1}\right)$ : 2936, 1773, 1730, 1646, 1496, 1430, 1322, 1288, 1251, 1205, 1184, 1092, 1054, 909, 851, 770; ESI-MS $[\mathrm{M}+\mathrm{H}]^{+}:$470.2; Anal. Calcd for $\mathrm{C}_{19} \mathrm{H}_{19} \mathrm{NO}_{13}: \mathrm{C}, 48.62 ; \mathrm{H}, 4.08 ; \mathrm{N}, 2.98$. Found: C, 48.71; H, 4.03; N, 3.03\%.

NO Donors Prolonged the Survival Time of Mice in Normobaric Hypoxia Test In the normobaric hypoxia test, the treatment with the NO donors significantly prolonged the survival time of oxygen deprivation mice (Table 1). Data showed that the AFIM had a dose-dependent effect of increasing the mice survival time exposed to hypoxia. The prolongation rates were 19.3\% (low dose), 58.8\% (middle dose), $64.5 \%$ (high dose) and 26.9\% (positive control) compare with vehicle, respectively.

Heart Rate and Blood Pressure Heart rate accelerate when the body's need to absorb oxygen and excrete carbon dioxide changes and was expressed as beats per minute (bpm). The heart rate increased significantly in hypobaric hypoxia model group while the blood pressure including systolic blood pressure (SBP), mean artery pressure (MAP) and diastolic blood pressure (DBP) decreased on the contrary. Treatment with NO donors could attenuated these changes compared with model (Fig. 2).

Lactic Acid We examined the lactic acid level of different groups in the normobaric hypoxia test. There were not significant changes during each group, but the treatment with the

Table 1. Effects of NO Donor Compounds on the Survival Time of Mice under Normobaric Hypoxia Condition $(n=10)$

\begin{tabular}{|c|c|c|c|}
\hline Name & Dose $(\mathrm{mg} / \mathrm{kg})$ & Survival time (min) & Prolonged rate $(\%)$ \\
\hline Vehicle & - & $30.1 \pm 1.2$ & - \\
\hline Acetazolamide & 200 & $38.2 \pm 5.1 *$ & 26.9 \\
\hline $\mathrm{A}$ & 100 & Death & - \\
\hline \multirow[t]{3}{*}{$\mathrm{B}$} & 50 & $35.9 \pm 5.1^{*}$ & 19.3 \\
\hline & 75 & $47.8 \pm 9.8 * *$ & 58.8 \\
\hline & 100 & $49.5 \pm 10.5 * *$ & 64.5 \\
\hline $\mathrm{C}$ & 100 & $37.8 \pm 11.0^{*}$ & 25.6 \\
\hline $\mathrm{D}$ & 100 & $37.5 \pm 5.4^{*}$ & 24.6 \\
\hline $\mathrm{E}$ & 100 & $34.7 \pm 3.2$ & 8.3 \\
\hline $\mathrm{F}$ & 100 & $48.6 \pm 14.6^{* *}$ & 61.5 \\
\hline G & 40 & $44.7 \pm 11.5^{*}$ & 48.5 \\
\hline
\end{tabular}

A: $(1 S, 4 S, 5 S, 8 R)-8$-Nitrooxy-2,6-dioxabicyclo[3.3.0]octan-4-yl-3-(4-acetoxyphenyl)acrylate; B: (1S,4S,5S,8R)-8-Nitrooxy-2,6-dioxabicyclo[3.3.0]octan-4-yl-3-(3-methoxyl-4acetoxyphenyl)acrylate; C: $(1 S, 4 S, 5 S, 8 R)$-8-Nitrooxy-2,6-dioxabicyclo[3.3.0]octan-4-yl-3-(3,4-diacetoxyphenyl)acrylate; D: (1S,4S,5S,8R)-8-Nitrooxy-2,6-dioxabicyclo[3.3.0] octan4-yl-4-acetoxybenzoate; E: $(1 S, 4 S, 5 S, 8 R)$-8-Nitrooxy-2,6-dioxabicyclo[3.3.0]octan-4-yl-3,4-diacetoxybenzoate; F: $(1 S, 4 S, 5 S, 8 R)-8$-Nitrooxy-2,6-dioxabicyclo[3.3.0] octan-4-yl-3,4,5triacetoxybenzoate; G: Isosorbide mononitrate. Each group represents the mean \pm S.D. ${ }^{*} p<0.05 v s$. Vehicle. $* * p<0.01 v s$. Vehicle. 

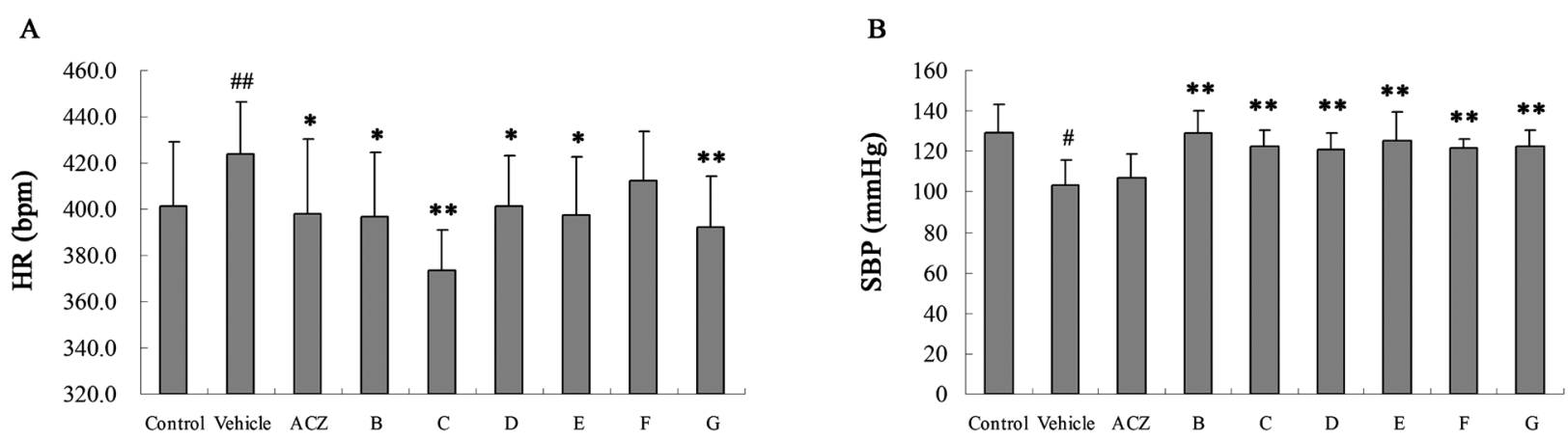

C
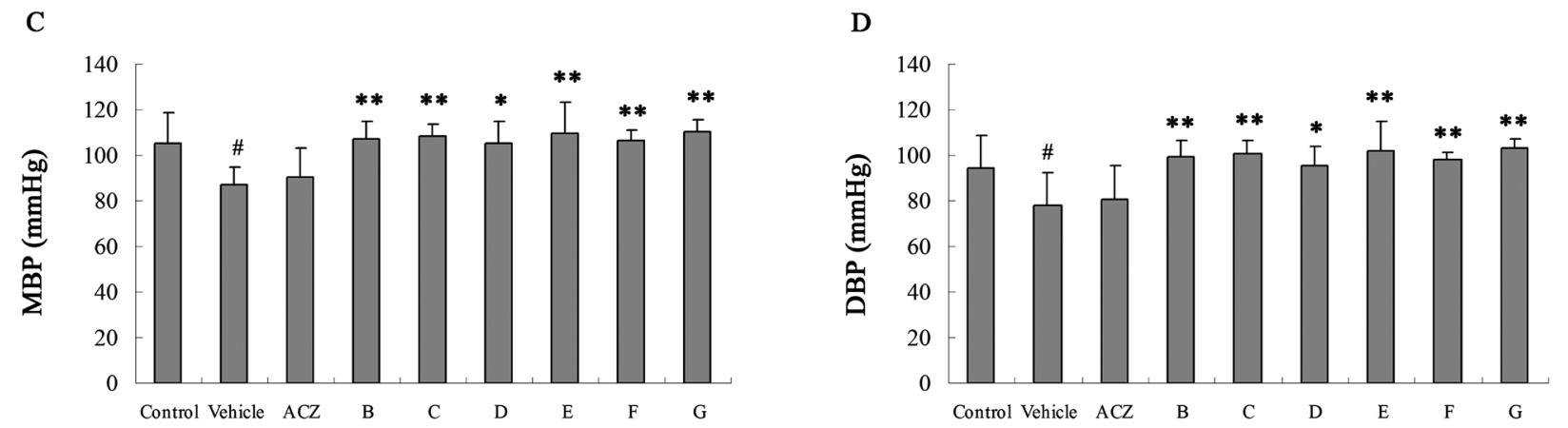

Fig. 2. Effects of NO Donors on Heart Rate and Blood Pressure of Rats under Hypobaric Hypoxia Condition $(n=10)$

A: Heart rate (bpm); B: Blood pressure (SBP); C: Mean artery pressure (MAP); D: Diastolic blood pressure (DBP). ${ }^{\#} p<0.05 v s$. Control. ${ }^{\# \#} p<0.01 v s$. Control. ${ }^{*} p<0.05$ vs. Vehicle. ${ }^{* *} p<0.01$ vs. Vehicle.

A

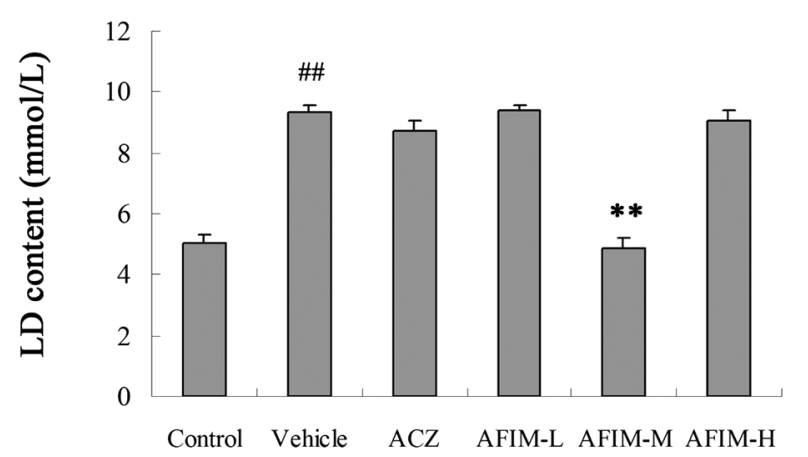

C

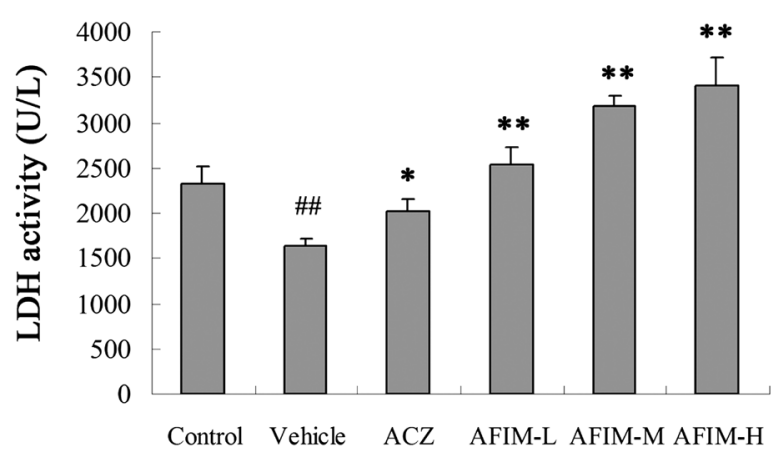

B

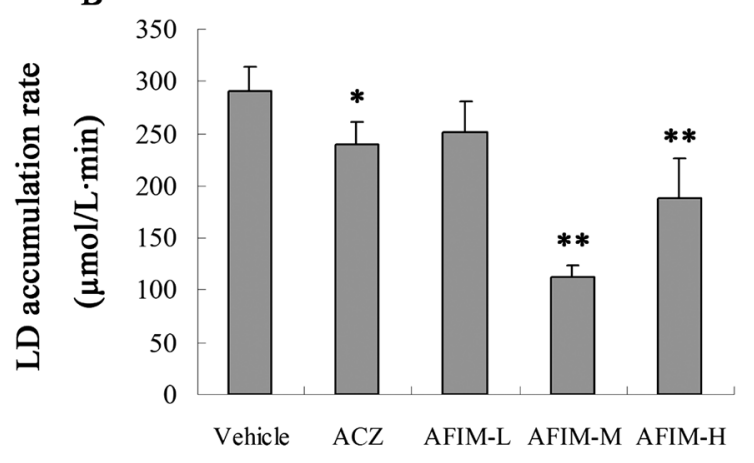

Fig. 3. Effects of AFIM on LD Content, LD Accumulation Rate and LDH Activity in Mice Plasma under Normobaric Hypoxia Condition ( $n=10)$ A: LD content $(\mathrm{mmol} / \mathrm{L})$; B: LD accumulation rate $(\mu \mathrm{mol} / \mathrm{L} \cdot \mathrm{min})$; C: $\mathrm{LDH}$ activity $(\mathrm{U} / \mathrm{L})$ Each group represents the mean \pm S.D. ${ }^{\# \#} p<0.01 v s$. Control. ${ }^{*} p<0.05 v s$. Vehicle. ${ }^{* *} p<0.01$ vs. Vehicle.

AFIM significantly decreased the lactic acid accumulation rate comparing with vehicle ${ }^{31)}$ (Fig. 3). The decrease rates of lactic acid accumulation rate were $13.6 \%$ (low dose), $61.2 \%$ (middle dose), 35.2\% (high dose) and 17.9\% (positive control) compare with model, respectively.

Activity of Lactate Dehydrogenase The activity of lactate dehydrogenase was coincidence with the trend of lactic acid accumulation rate. The treatment with the AFIM signifi- 
A

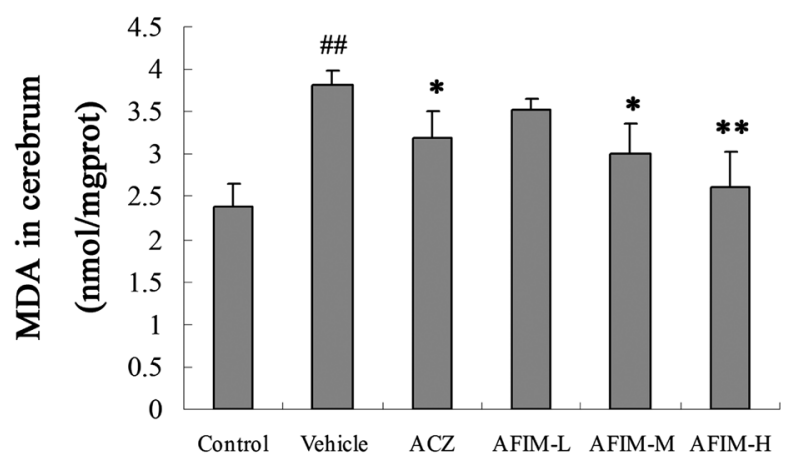

C

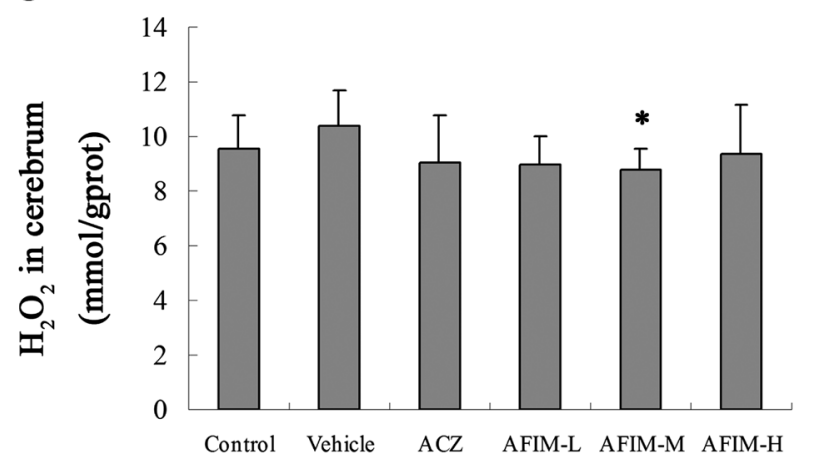

B
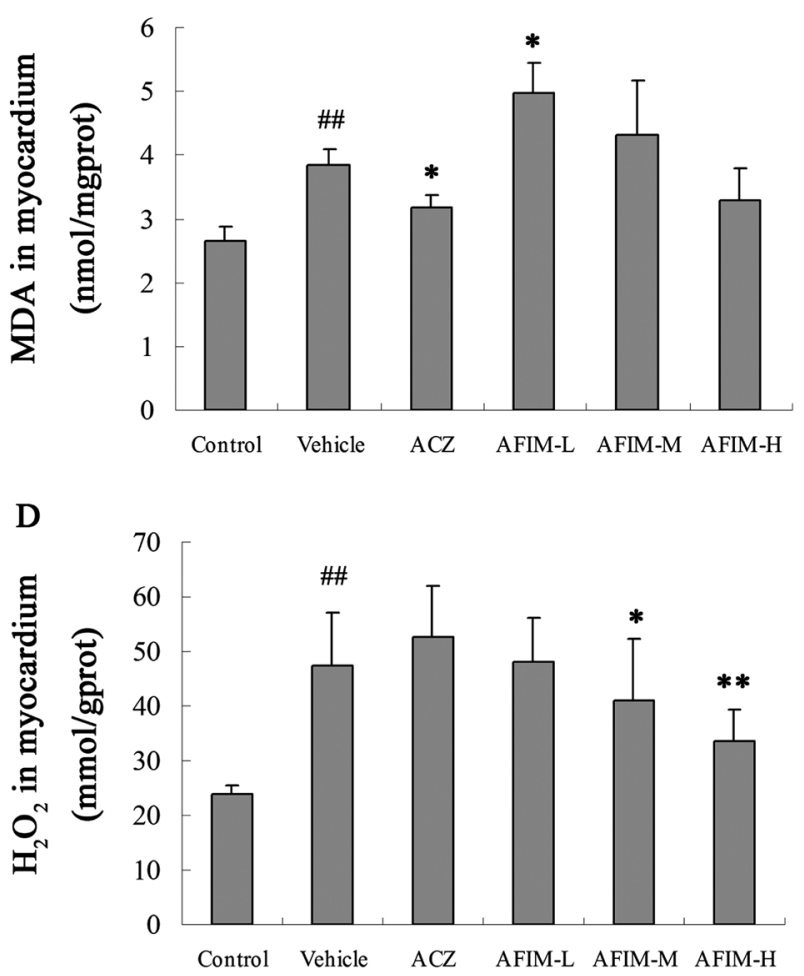

Fig. 4. Effects of AFIM on MDA and $\mathrm{H}_{2} \mathrm{O}_{2}$ in Mice Cerebrum and Myocardium under Hypobaric Hypoxia Condition ( $n=10$ )

A: MDA in mice cerebrum; B: MDA in mice myocardium; $\mathrm{C}: \mathrm{H}_{2} \mathrm{O}_{2}$ in mice cerebrum; $\mathrm{D}: \mathrm{H}_{2} \mathrm{O}_{2}$ in mice myocardium. ${ }^{\#} p<0.01$ vs. Control. $* p<0.05$ vs. Vehicle. $*_{*} p<0.01$ vs. Vehicle.

cantly decreased the lactate dehydrogenase activity comparing with model (Fig. 3).

MDA The level of malonaldehyde was coincidence with the trend of lactic acid accumulation rate. The treatment with the AFIM significantly decreased the MDA comparing with model (Fig. 4).

AFIM Directly Degrade Hypoxia-Induced $\mathrm{H}_{2} \mathrm{O}_{2}$ Production in Hypobaric Hypoxia Mice We determined production of $\mathrm{H}_{2} \mathrm{O}_{2}$ as an indication of ROS formation in mice brains and hearts after $6 \mathrm{~h}$ hypobaric hypoxia test. Hypoxia induced oxidative stress stimulated cerebrum and myocardium to increase $\mathrm{H}_{2} \mathrm{O}_{2}$ production compared to normal control. Treatment with AFIM significantly decreased $\mathrm{H}_{2} \mathrm{O}_{2}$ production in myocardium in hypobaric hypoxia mice model (Fig. 4). The degrading rate of $\mathrm{H}_{2} \mathrm{O}_{2}$ in AFIM $100 \mathrm{mg} / \mathrm{kg}$ group was $29.1 \%$ in mice myocardium compare with vehicle group.

Effect of the AFIM on the Activities of SOD, GSH-Px, CAT and ATP in Hypoxic Mice As the biomarker of the antioxidant defenses, the activity of SOD in cerebrum and myocardium, GSH and CAT in liver was measured (Fig. 5). The activities of SOD were conspicuous decreased in cerebrum and myocardium in vehicle. Activity of GSH-Px was also descent significantly. AFIM protected SOD activity in mice cerebrum compared with the vehicle group. There is no reduced GSH deficiency observed throughout the trial period at high doses of AFIM and ACZ compared with the vehicle group. The activity of CAT was increased compared with the control group. It was not descent but ascent, which probable because of the positive feedback regulation of $\mathrm{H}_{2} \mathrm{O}_{2}$. These results may indirectly indicate that the antioxidant enzymes in AFIM group had good antioxidant activities even after $12 \mathrm{~h}$ hypobaric hypoxia test.

Reduction of Cerebrum and Myocardium ATP Activities in Hypoxic Mice Mice cerebrum and myocardium ATP activities were examined using a luciferase assay kit. The biochemical activities of $\mathrm{Na}^{+}-\mathrm{K}^{+}$-ATPase, $\mathrm{Mg}^{2+}$-ATPase and $\mathrm{Ca}^{2+}$-ATPase in mice cerebrum and myocardium were significantly lower in vehicle group after $12 \mathrm{~h}$ hypoxia treatment compared with normal control group. On the contrary AFIM lessened the decrement of three kinds of ATPase in hypoxic mice cerebrum and myocardium compare to vehicle group. The data showed that AFIM had a dose-dependent effect (Fig. $6)$.

\section{DISCUSSION}

Previous work had found inhalation of NO improved survival in the rat model of HAPE, improved arterial oxygenation in high-altitude pulmonary edema, and may have a therapeutic role in the management of HAPE. ${ }^{18,19)}$ The combined using of inhaled NO and oxygen had additive effects on pulmonary hemodynamic and even greater effects on gas exchange. The beneficial effect may be related to its favorable action on the distribution of blood flow in the lungs. ${ }^{17)}$ Augmented endogenous NO production, especially at higher altitudes, accounted for the low pulmonary vascular tone observed in high-altitude adapted yaks. ${ }^{16)}$ In our current work we found the administration of NO donor compounds prolonged the survival time of mice under normobaric hypoxia. NO donors also maintained the heart rate, SBP, MAP and DBP at normal level. The protective results may come from the protective effects for brain and hearts. The toxicity of compound A may 
A

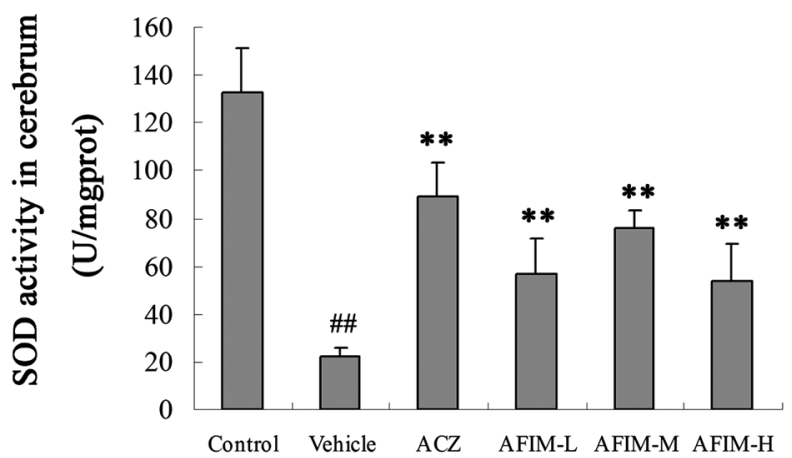

C

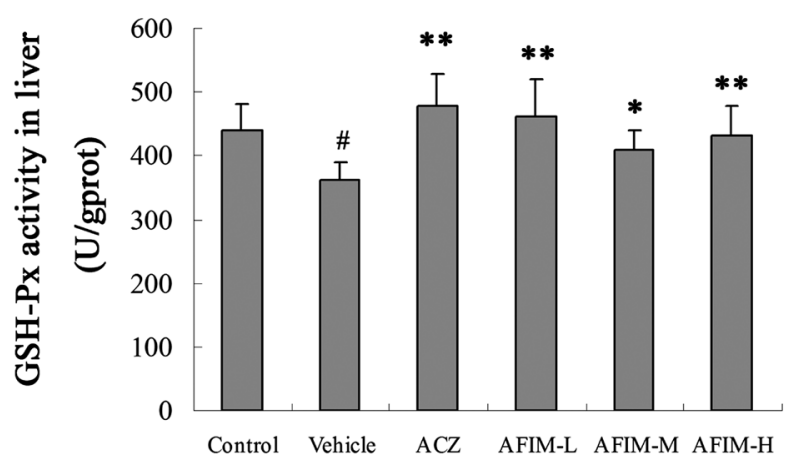

B

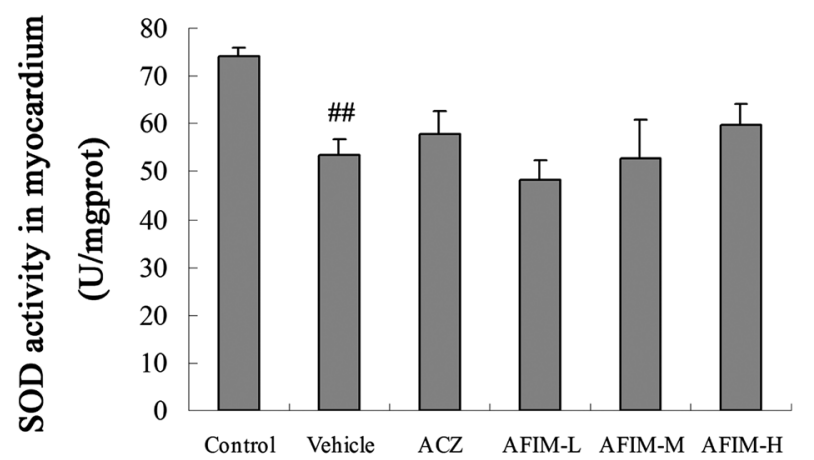

D

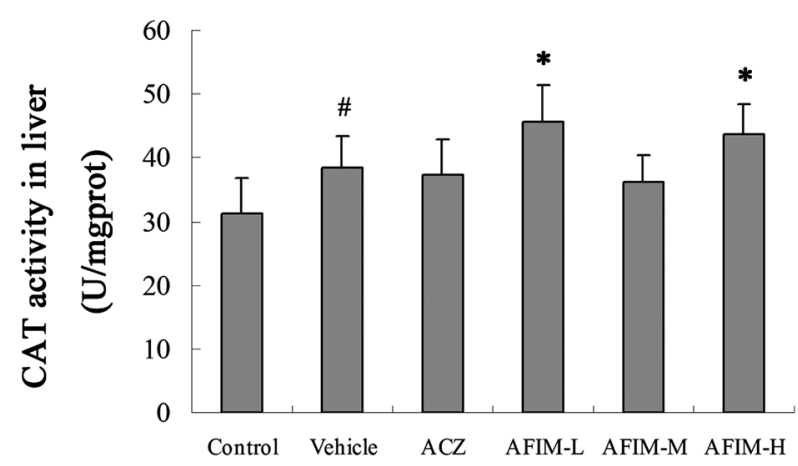

Fig. 5. Effects of AFIM on SOD in Mice Cerebrum and Myocardium, GSH-Px, CAT in Liver, under Hypobaric Hypoxia Condition ( $n=10$ )

A: SOD activity in cerebrum; B: SOD activity in myocardium; C: GSH-Px activity in liver; D: CAT activity in liver. ${ }^{\#} p<0.05 v s$. Control. ${ }^{\#} p<0.01 v s$. Control. $* p<0.05$ vs. Vehicle. $* * p<0.01$ vs. Vehicle.

come from the parent structure coumaric acid $\left(\mathrm{LD}_{50} 657 \mathrm{mg} /\right.$ $\mathrm{kg}$, intraperitoneally (i.p.)) while other NO donors showed good safety. ${ }^{32)}$

During reoxygenation, ROS production markedly accelerates, causing further suppression of electron transport, which promotes greater ROS production, etc., in a vicious cycle. NO inhibits this scenario, potentially contributing to its cardio protective effects when administered at the time of reoxygenation in intact heart. ${ }^{33)}$ An efficient free radical scavenger need not only prevent the initiation of protein damage (by scavenging the initial attacking radicals), but also be effective interception of protein radicals once they are formed. The latter is a challenging problem due to the high concentration of potential radical targets present in biological fluids and cells. Previous research found that long-lived radicals such as nitroxides (RR'NO) and NO might be efficient scavengers of protein-derived radicals. ${ }^{34)}$ For aim to discover new long half-life NO species, we synthesized series of isosorbide mononitrate derivants as $\mathrm{NO}$ donor compounds and tested their anti-hypoxia activities through the survival time of the mice under normobaric hypoxia. Among those compounds, AFIM was the most effective one (Table 1). Also isosorbide mononitrate showed good anti-hypoxia activities during hypoxia test, but the side effect was significant when the dose was higher than $40 \mathrm{mg} / \mathrm{kg}$.

Unlike other radical these isosorbide mononitrate derivants NO donor compounds were stable in biological fluids and have long half-life which meet the requirement for competitive reaction as a free radical scavenger. They might be efficient scavengers of protein-derived radicals, as the reactions with radical should have low energy barriers, being radical-radical reactions, and have rate constants near the diffusion limit. ${ }^{35)}$

NO donors' protective effects may come from two aspects. One was from the higher blood flow and circulating NO products offset high-altitude hypoxia, the other was from their clearance for radical molecules as stable free radical scavengers. As AFIM was the most effective one during the normobaric hypoxia test, it was consisted of isosorbide mononitrate residues and acetyl ferulic acid residues. Ferulic acid exerts a neuroprotective effect in cerebral ischemia through its anti-oxidant and anti-inflammation activity. ${ }^{35,36)}$ Its protective effect might come from the sustained NO supplying and the anti-oxidant activity of acetyl ferulic acid.

The enhanced radical scavenging capacities of the novel nitronyl nitroxides may be potential drug leads against the deleterious action of reactive oxygen species (ROS)/reactive nitrogen species (RNS). ${ }^{25}$ ) Providing exogenous nitric oxide dramatically prevents $\mathrm{H}_{2} \mathrm{O}_{2}$-mediated endothelial injury, likely by reducing iron-mediated oxidant generation and subsequent lipid peroxidation. ${ }^{37)}$ The mechanism of the protected effect may be explained by high affinity binding of $\mathrm{NO}$ to $\mathrm{Fe}^{2+}$, limiting $\mathrm{Fe}^{2+}$ oxidation by Fenton reaction. It may seem surprising that NO protects cells exposed not only to exogenous $\mathrm{H}_{2} \mathrm{O}_{2}{ }^{32)}$ but also to enzymatic systems generating $\left.\mathrm{O}_{2}^{-\cdot}, 37,38\right)$ since NO can react with $\mathrm{O}_{2}^{-\cdot}$ to generate peroxynitrite radicals. AFIM has been previously shown to confer improved resistance against ischemic/reperfused injury ${ }^{39)}$; we wished to verify that it could also protect the antioxidase activity in hypobaric hypoxia mice. This study showed AFIM prolonged the mice survival time during normobaric hypoxia test, decrease MDA and $\mathrm{H}_{2} \mathrm{O}_{2}$ in brain and heart of the mice under hypobaric hypoxia test. AFIM also maintained the activities 
A

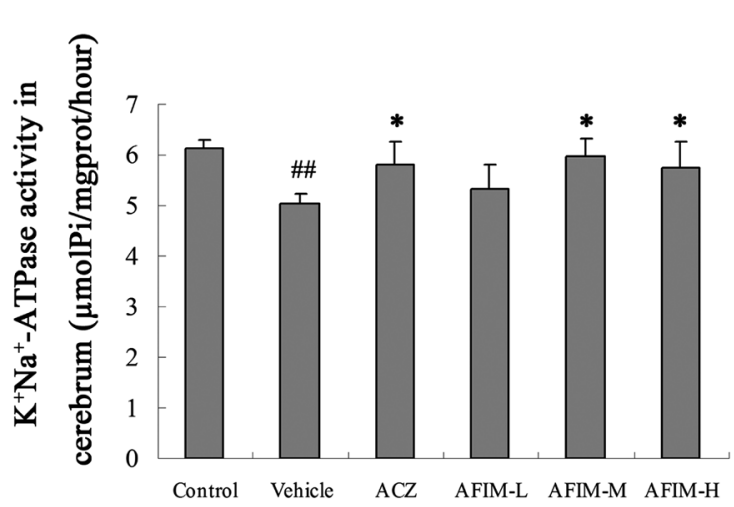

C

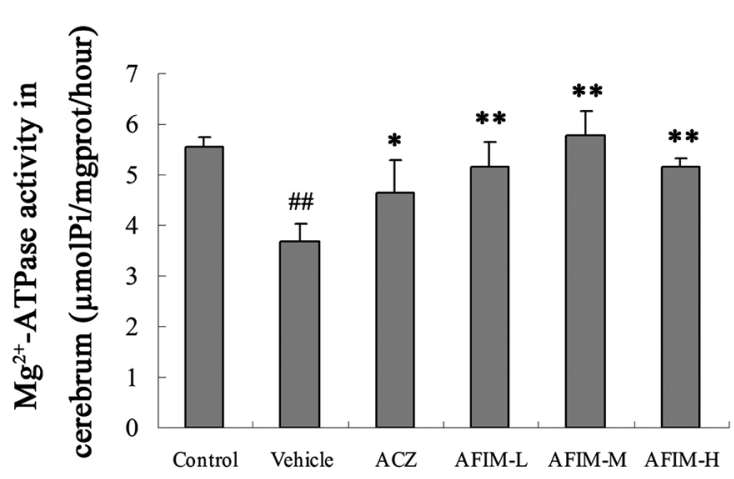

E

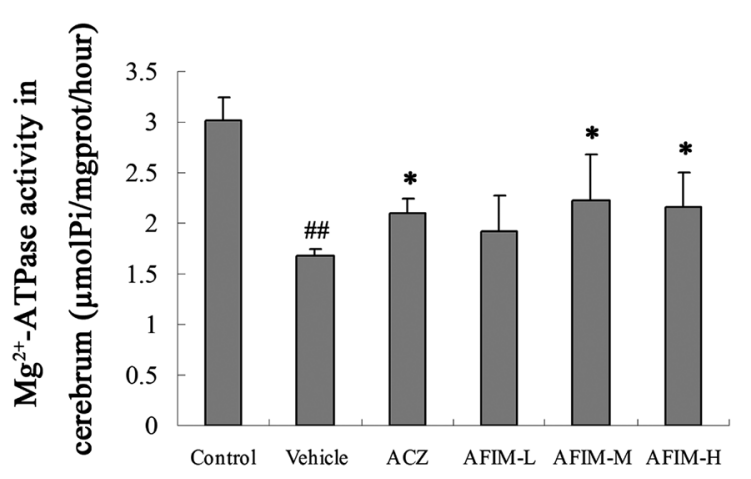

B

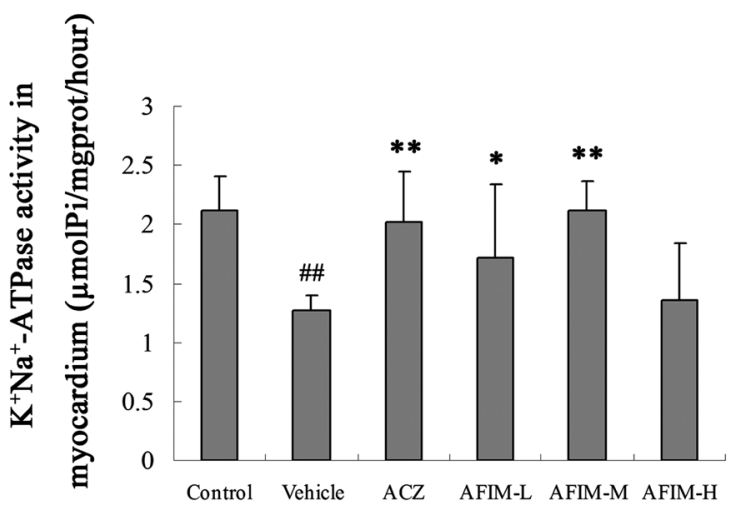

D

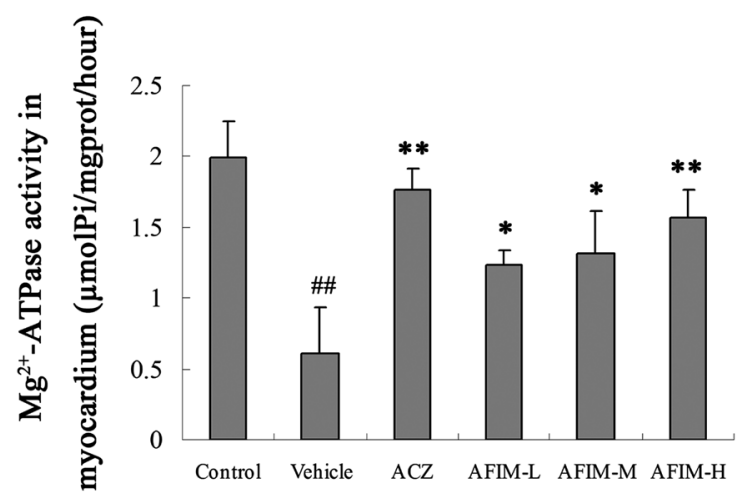

F

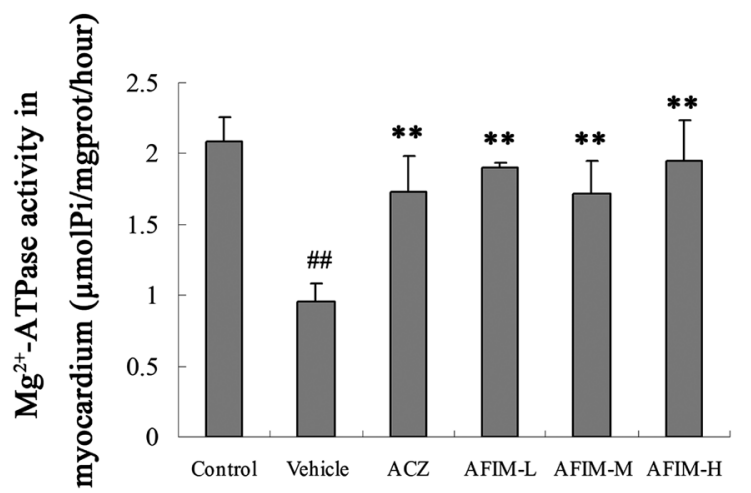

Fig. 6. Effects of AFIM on ATPase Activity in Mice Cerebrum and Myocardium under Hypobaric Hypoxia Condition ( $n=10)$

A: $\mathrm{K}^{+} \mathrm{Na}^{+}$-ATPase activity in mice cerebrum; B: $\mathrm{K}^{+} \mathrm{Na}^{+}$-ATPase activity in mice myocardium; $\mathrm{C} \mathrm{Mg}^{2+}$-ATPase activity in mice cerebrum; D: Mg ${ }^{2+}$-ATPase activity in mice myocardium; E: $\mathrm{Ca}^{2+}$-ATPase activity in mice myocardium; $\mathrm{F}: \mathrm{Ca}^{2+}$-ATPase activity in mice myocardium. ${ }^{\#} p<0.05$ vs. Control. ${ }^{\#} p<0.01$ vs. Control. ${ }^{*} p<0.05$ vs. Vehicle. ${ }^{* *} p<0.01$ vs. Vehicle.

of SOD, GSH-Px and CAT within a normal range.

As a major oxidation product of membrane peroxidized polyunsaturated fatty acids MDA is an indicator for oxidative stress. ${ }^{40)}$ MDA content level in hypobaric hypoxia mice changed significantly, which indicated that lipid peroxidation occurred in early hypoxia stage. AFIM significantly decreased MDA in mice cerebrum and myocardium in hypobaric hypoxia group. Comparing to normal control, hypoxia-induced oxidative stress stimulated $\mathrm{H}_{2} \mathrm{O}_{2}$ production increase especially in myocardium. Treatment with AFIM could significantly decrease $\mathrm{H}_{2} \mathrm{O}_{2}$ in myocardium in hypobaric hypoxia mice model. Human antioxidant defense system is equipped with enzymatic scavengers, such as SOD, GSH-Px and CAT, hydrophilic scavengers, e.g. glutathione and lipophilic radical- scavengers, such as tocopherols. ${ }^{41)}$ The enzymatic activities of these antioxidases were critical for the clearance of free radical. It may be beneficial if antioxidase activity could be maintained or increased. The finding that AFIM could protect mice myocardium against hypoxia-induced $\mathrm{H}_{2} \mathrm{O}_{2}$ could have resulted from the direct decomposition of $\mathrm{H}_{2} \mathrm{O}_{2}$ or from an increase in the activities of $\mathrm{H}_{2} \mathrm{O}_{2}$-degrading enzymes. We found that the activities of SOD and GSH-Px were down-regulated after hypobaric hypoxia treatment, which result in superoxide anion-scavenging activity decrease and oxidative damage to the organism. This might partially explained the increase of $\mathrm{H}_{2} \mathrm{O}_{2}$ and MDA in myocardium as there were not sufficient cellular antioxidants. Interestingly the activities of SOD, GSH-Px and CAT showed different trends during the hypoxia 
progress in current study. Unlike SOD and GSH-Px, the activity of CAT was up-regulated. This may attributed to the back donation of increased $\mathrm{H}_{2} \mathrm{O}_{2}$ in myocardium. As a sign of mitochondrial dysfunction the activities of ATPase were down regulated. AFIM protected mitochondria in hypobaric hypoxia treatment by scavenging free radical.

\section{CONCLUSION}

In conclusion, we found that mice administrated with AFIM could survive longer than ACZ group. We also found that AFIM was more effective to protect antioxidase than ACZ in hypobaric hypoxia mice model. Intravenous administration NO donor compounds had the same beneficial effects as inhaled NO for circulatory system and nervous system. Our result suggested that NO donor administration might be a potential therapeutic way for prophylaxis and therapy of acute high-altitude sickness.

Acknowledgments The authors wish to acknowledge support from the Chinese National Natural Science Foundation Grant Number 81402848 and the Gansu Natural Science Foundation Grant Number 145RJDA331.

Conflict of Interest The authors declare no conflict of interest.

\section{REFERENCES}

1) Krampl E. Pregnancy at high altitude. Ultrasound Obstet. Gynecol., 19, 535-539 (2002).

2) Imray $C$, Wright A, Subudhi A, Roach R. Acute mountain sickness: pathophysiology, prevention, and treatment. Prog. Cardiovasc. Dis., 52, 467-484 (2010).

3) Moraga FA, Flores A, Serra J, Esnaola C, Barriento C. Ginkgo biloba decreases acute mountain sickness in people ascending to high altitude at Ollague $(3696 \mathrm{~m})$ in northern Chile. Wilderness Environ. Med., 18, 251-257 (2007).

4) Bärtsch P, Mairbaurl H, Maggiorini M, Swenson ER. Physiological aspects of high-altitude pulmonary edema. J. Appl. Physiol., 98, 1101-1110 (2005)

5) Fagan KA, McMurtry IF, Rodman DM. Role of endothelin-1 in lung disease. Respir. Res., 2, 90-101 (2001).

6) Hackett PH, Roach RC. High altitude cerebral edema. High Alt. Med. Biol., 5, 136-146 (2004).

7) Basnyat B, Gertsch JH, Johnson EW, Castro-Marin F, Inoue Y, Yeh C. Efficacy of low-dose acetazolamide (125 mg BID) for the prophylaxis of acute mountain sickness: a prospective, double-blind, randomized, placebo-controlled trial. High Alt. Med. Biol., 4, 45-52 (2003).

8) Moore LG, Charles SM, Julian CG. Humans at high altitude: hypoxia and fetal growth. Respir. Physiol. Neurobiol., 178, 181-190 (2011).

9) Seupaul RA, Welch JL, Malka ST, Emmett TW. Pharmacologic prophylaxis for acute mountain sickness: a systematic shortcut review. Ann. Emerg. Med., 59, 307-317 el (2012).

10) Leshem E, Caine Y, Rosenberg E, Maaravi Y, Hermesh H, Schwartz E. Tadalafil and acetazolamide versus acetazolamide for the prevention of severe high-altitude illness. J. Travel Med., 19, 308-310 (2012)

11) Ritchie ND, Baggott AV, Andrew Todd WT. Acetazolamide for the prevention of acute mountain sickness - a systematic review and meta-analysis. J. Travel Med., 19, 298-307 (2012).

12) MacInnis MJ, Carter EA, Koehle MS, Rupert JL. Exhaled nitric oxide is associated with acute mountain sickness susceptibility during exposure to normobaric hypoxia. Respir. Physiol. Neurobiol., 180, 40-44 (2012).

13) Erzurum SC, Ghosh S, Janocha AJ, Xu W, Bauer S, Bryan NS, Tejero J, Hemann C, Hille R, Stuehr DJ, Feelisch M, Beall CM. Higher blood flow and circulating NO products offset high-altitude hypoxia among Tibetans. Proc. Natl. Acad. Sci. U.S.A., 104, 1759317598 (2007).

14) Hoit BD, Dalton ND, Erzurum SC, Laskowski D, Strohl KP, Beall CM. Nitric oxide and cardiopulmonary hemodynamics in Tibetan highlanders. J. Appl. Physiol., 99, 1796-1801 (2005).

15) Beall CM. Two routes to functional adaptation: Tibetan and Andean high-altitude natives. Proc. Natl. Acad. Sci. U.S.A., 104 (Suppl. 1), 8655-8660 (2007).

16) Ishizaki T, Koizumi T, Ruan Z, Wang Z, Chen Q, Sakai A. Nitric oxide inhibitor altitude-dependently elevates pulmonary arterial pressure in high-altitude adapted yaks. Respir. Physiol. Neurobiol., 146, 225-230 (2005).

17) Scherrer U, Vollenweider L, Delabays A, Savcic M, Eichenberger U, Kleger GR, Fikrle A, Ballmer PE, Nicod P, Bartsch P. Inhaled nitric oxide for high-altitude pulmonary edema. N. Engl. J. Med., 334, 624-630 (1996).

18) Anand IS, Prasad BA, Chugh SS, Rao KR, Cornfield DN, Milla CE, Singh N, Singh S, Selvamurthy W. Effects of inhaled nitric oxide and oxygen in high-altitude pulmonary edema. Circulation, 98, 2441-2445 (1998).

19) Omura A, Roy R, Jennings T. Inhaled nitric oxide improves survival in the rat model of high-altitude pulmonary edema. Wilderness Environ. Med., 11, 251-256 (2000).

20) Kronenberg RS, Cain SM. Effects of acetazolamide on physiologic and subjective responses of men to 14000 feet. SAM-TR-67-81. Tech. Rep. SAM-TR, 1967, 1-10 (1967).

21) Ma HP, Fan PC, Jing LL, Yao J, He XR, Yang Y, Chen KM, Jia ZP. Anti-hypoxic activity at simulated high altitude was isolated in petroleum ether extract of Saussurea involucrata. J. Ethnopharmacol., 137, 1510-1515 (2011).

22) Low EV, Avery AJ, Gupta V, Schedlbauer A, Grocott MP. Identifying the lowest effective dose of acetazolamide for the prophylaxis of acute mountain sickness: systematic review and meta-analysis. BMJ, 345, e6779 (2012).

23) Yang MT, Chien WL, Lu DH, Liou HC, Fu WM. Acetazolamide impairs fear memory consolidation in rodents. Neuropharmacology, 67, 412-418 (2013).

24) Pun M. Side-effect of acetazolamide in prevention of acute mountain sickness. S. Afr. Med. J., 102, 114, author reply, 114 (2012).

25) Wu Y, Bi L, Bi W, Li Z, Zhao M, Wang C, Ju J, Peng S. Novel 2-substituted nitronyl nitroxides as free radical scavengers: synthesis, biological evaluation and structure-activity relationship. Bioorg. Med. Chem., 14, 5711-5720 (2006).

26) Fan PC, Ma HP, Jing LL, Li L, Jia ZP. The antioxidative effect of a novel free radical scavenger 4'-hydroxyl-2-substituted phenylnitronyl nitroxide in acute high-altitude hypoxia mice. Biol. Pharm. Bull., 36, 917-924 (2013).

27) Hu X, Zhou X, He B, Xu C, Wu L, Cui B, Wen H, Lu Z, Jiang H. Minocycline protects against myocardial ischemia and reperfusion injury by inhibiting high mobility group box 1 protein in rats. Eur. J. Pharmacol., 638, 84-89 (2010).

28) Mihara M, Uchiyama M. Determination of malonaldehyde precursor in tissues by thiobarbituric acid test. Anal. Biochem., 86, 271-278 (1978).

29) Deng $X, W u F$, Liu Z, Luo M, Li L, Ni Q, Jiao Z, Wu M, Liu Y. The splenic toxicity of water soluble multi-walled carbon nanotubes in mice. Carbon, 47, 1421-1428 (2009).

30) Wang QS, Zhang CL, Zhao XL, Yu SF, Xie KQ. Malondialdehyde and catalase as the serum biomarkers of allyl chloride-induced toxic neuropathy. Toxicology, 227, 36-44 (2006). 
31) Young RS, Petroff OA, Aquila WJ, Cheung A, Gore JC. Hyperglycemia and the rate of lactic acid accumulation during cerebral ischemia in developing animals: in vivo proton MRS study. Biol. Neonate, 61, 235-242 (1992).

32) Ohta S, Furukawa M, Shinoda M. Studies on chemical protectors against radiation. XXIII. Radioprotective activities of ferulic acid and its related compounds. Yakugaku Zasshi, 104, $793-797$ (1984).

33) Korge P, Ping P, Weiss JN. Reactive oxygen species production in energized cardiac mitochondria during hypoxia/reoxygenation: modulation by nitric oxide. Circ. Res., 103, 873-880 (2008).

34) Lam MA, Pattison DI, Bottle SE, Keddie DJ, Davies MJ. Nitric oxide and nitroxides can act as efficient scavengers of proteinderived free radicals. Chem. Res. Toxicol., 21, 2111-2119 (2008).

35) Sung JH, Kim MO, Koh PO. Ferulic acid attenuates the focal cerebral ischemic injury-induced decrease in parvalbumin expression. Neurosci. Lett., 516, 146-150 (2012).

36) Koh PO. Ferulic acid prevents cerebral ischemic injury-induced reduction of hippocalcin expression. Synapse, 67, 390-398 (2013).
37) Chang J, Rao NV, Markewitz BA, Hoidal JR, Michael JR. Nitric oxide donor prevents hydrogen peroxide-mediated endothelial cell injury. Am. J. Physiol., 270, L931-L940 (1996).

38) Wink DA, Hanbauer I, Krishna MC, DeGraff W, Gamson J, Mitchell JB. Nitric oxide protects against cellular damage and cytotoxicity from reactive oxygen species. Proc. Natl. Acad. Sci. U.S.A., 90, 9813-9817 (1993).

39) Liu WC, Sun XL, Ji LL, Wang HB, Zhang HF, Li J, Shi L, Jing LL, Gao F. Synthesis and cardioprotective effect of a novel anti-ischemic/reperfused injury compound. Yао Хие Хие Вao, 44, 321-326 (2009).

40) Freeman BA, Crapo JD. Hyperoxia increases oxygen radical production in rat lungs and lung mitochondria. J. Biol. Chem., 256, 10986-10992 (1981).

41) Ratnam DV, Ankola DD, Bhardwaj V, Sahana DK, Kumar MN. Role of antioxidants in prophylaxis and therapy: A pharmaceutical perspective. J. Control. Release, 113, 189-207 (2006). 